Cómo citar este trabajo: Fernández Cela, J. C. (2019). Estructura espacial de los centros financieros offshore en Europa. Boletín de la Asociación de Geógrafos Españoles, 80, 2646, 1-30. http://dx.doi.org/10.21138/bage.2546a

\title{
Estructura espacial de los centros financieros offshore en Europa
}

\author{
Spatial structure of the offshore financial centers in Europe
}

\author{
Juan Carlos Fernández Cela \\ juancarlosfernandezcela@yahoo.es \\ Departamento de Historia, Teorías y Geografía Políticas \\ Universidad Complutense de Madrid (España)
}

\section{Resumen}

Se ha analizado para toda Europa la red espacial de conexiones societarias internacionales filtradas en los denominados papeles de Panamá. Esto ha permitido conocer la morfología espacial de la estructura financiera de evasión de capital desde Europa a paraísos fiscales de todo el mundo. También permite elaborar una cartografía de flujos de capital financiero en Europa que identifica sus puntos de origen, tránsito y destino. El resultado revela la existencia de diferentes espacios financieros en el interior del continente, así como territorios fuera de Europa que se encuentran bajo el control geopolítico de la UE, y que constituyen nodos críticos como destino final del capital. El más importante con diferencia pertenece a los restos del imperio colonial inglés. Se trata de un espacio utilizado por Reino Unido para establecer una red financiera mundial que tiene su epicentro en la City y su destino final en las Islas Vírgenes Británicas.

Palabras clave: geografía financiera; flujos transnacionales de capital; papeles de Panamá; inteligencia financiera; paraísos fiscales.

\footnotetext{
Abstract

The spatial network of international corporate connections filtered in the so-called Panama papers has been analysed for the whole of Europe. This has allowed us to know the spatial morphology of the financial structure of capital evasion from Europe to tax havens around the world. It also makes it possible to map financial capital flows in Europe, identifying their points of origin, transit and 
destination. The result reveals the existence of different financial spaces within the continent, as well as territories outside Europe that are under the geopolitical control of the EU, and which constitute critical nodes as the final destination of capital. The most important by far belongs to the remains of the English colonial empire. It is a space used by the United Kingdom to establish a global financial network with its epicentre in the City and its final destination in the British Virgin Islands.

Key words: financial geography; transnational capital flows; Panama papers; financial intelligence; tax havens.

\section{Introducción}

La dimensión territorial de los flujos transnacionales es un fenómeno que se encuentra en pleno debate como consecuencia del renovado interés que, tras la crisis económica, han suscitado los estudios de contagio entre países con elevado nivel de riesgo en los mercados financieros internacionales (Milessi-Ferreti et. al., 2010).

Una creciente financiarización de la economía, ligada a la modificación de los patrones espaciales de desplazamiento de los circuitos de valor y de los flujos espaciales del crédito y la deuda, está poniendo de manifiesto la importancia que el territorio representa en este fenómeno. Este factor contribuye entre otros a explicar por qué la crisis económica adquirió una dimensión global, y su dispersión por todo el espacio ha sido tan rápida y relevante. Una geografía económica vinculada al análisis de los flujos de capital financiero y su impacto en los territorios puede desempeñar un importante papel a la hora de estudiar estos aspectos, y avanzar en el conocimiento de los mecanismos de difusión espacial del modelo de producción capitalista (Sokol, 2013; Aalbers, 2017).

El interés de los expertos en esta materia se plantea desde una doble perspectiva. En el primero de los casos, los trabajos sobre financiarización centran su interés en el impacto que los flujos financieros internacionales ejercen sobre el territorio, y su función en la estructura espacial de lo que algunos denominan como "redes financieras globales" (Coe, Lai \& Wójcik, 2014). Según este planteamiento, las diferencias entre países son una cuestión relevante a la hora de explicar el comportamiento de los flujos internacionales de capital financiero (Corpataux, Crevoisier \& Theurillat, 2017). Existe así un paralelismo entre la configuración de los sistemas de financiarización en los distintos territorios y el desarrollo de la integración de unos mercados que suministran "materia prima básica", en forma de capital, destinadas a inversiones productivas u operaciones especulativas en sectores estratégicos de terceros estados.

No todos los expertos están de acuerdo en la importancia del elemento geográfico en las transmisiones de riesgo entre países. Un análisis de las relaciones bursátiles entre 41 países desarrollados durante 16 años señala que elementos geográficos como es la cercanía espacial, la 
interdependencia de sus mercados o una similar estructura industrial son factores que incrementan las conexiones entre mercados financieros. Sin embargo en ningún caso son determinantes. Factores de interdependencia económica, como la tasa de retorno esperado de inversiones y la volatilidad de los tipos de cambio, tienen un peso superior en las relaciones entre mercados que la cercanía geográfica (Asgharian, Hess, \& Liu, 2013).

Junto a estudios de carácter general, se ha avanzado en poco tiempo sobre algunos trabajos de casos particulares. El análisis de los conglomerados organizativos de grandes sociedades en distintos territorios, como es el caso de HSBC, es uno de los más completos (Knight \& Wójcik, 2017). La integración de las redes financieras societarias y su influencia en el comercio de divisas sugiere la existencia de una tendencia a la concentración espacial de las operaciones de moneda en los centros financieros de Londres y Nueva York (Wojcik, MacDonald-Kort \& Zhao, 2017). En lo que respecta a operaciones especulativas en el interior de países, estudios de casos han detectado correlaciones espaciales muy concretas como es el caso de la influencia de los derivados en el mercado agrícola de Chicago en la configuración financiera de Estado Unidos (Muellerleile, 2015).

La segunda línea de trabajo está ligada a determinar la morfología de los flujos de capital entre países. En este caso lo que se pretende es reconstruir la lógica, estructura, composición, desequilibrios y sistemas de relaciones espaciales que genera la movilidad del capital financiero. La correlación entre capital y territorio es asimétrica y desigual. Existen en estos casos centros financieros internacionales que ejercen como elementos de transmisión del capital entre espacios, que desempeñan un papel clave a la hora de perfilar una cartografía de movimientos e inversiones entre países. Así, algunos estudios sugieren que tras la crisis económica se ha producido un desplazamiento de los ejes financieros desde Nueva York hacia los centros de Tokio y Londres. La capacidad de influencia de la Bolsa neoyorquina en el volumen de negociación es crecientemente menor desde 2007. Se sugiere que una parte de este cambio estaría vinculado con la crisis de deuda de los países sur de la UE, que ha beneficiado la centralidad espacial de Londres en detrimento de Nueva York (Ibrahim, Brzeszczyński \& Bhattacharjee, 2017). La implementación de algoritmos en la decisión de inversiones internacionales no solo no invalida sino que acrecienta la importancia de las pautas de localización del capital entre países debido a las asimetrías en el acceso a la información (Zook \& Grote, 2017).

Aun no siendo una rama plenamente consolidada, los trabajos de geografía financiera están abordando estos problemas y permiten ofrecer una visión diferente sobre las relaciones económicas entre países, y sus implicaciones en otros aspectos de carácter geopolítico que pueden incluso afectar a cuestiones de seguridad nacional. Se considera que, en determinadas situaciones, el impacto de estos movimientos pueden ejercer un efecto desestabilizador en el resto de la economía 
y de la sociedad, incrementando los desequilibrios en el reparto de riqueza y poniendo en peligro algunos componentes básicos del estado de bienestar (Fernández Cela, 2018).

En lo que respecta al interés sobre delitos financieros y evasión fiscal se dispone de abundante bibliografía, y como consecuencia de la crisis económica, ha salido a un primer plano en su difusión pública internacional (Johannesen, Langetieg, Reck, Risch \& Slemrod, 2018). Se estima que en torno a un $10 \%$ del PIB mundial se encuentra oculto en centros financieros offshore, una cifra que pone de manifiesto su impacto sobre las balanzas fiscales de los países que, como el caso de España, se han visto afectados de lleno por la crisis y el déficit público (Alstadsæter, Johannesen \& Zucman, 2017). Menos atención se ha prestado a la estructura espacial diseñada por las sociedades financieras internacionales para la evasión fiscal. La posibilidad de comisión de delitos financieros a gran escala solo es posible elaborando una compleja estructura societaria articulada entre distintos países que dificulte la identificación de los activos y sus verdaderos propietarios (Dyreng \& Lindsey, 2009). La inexistencia de trabajos de estas características no se debe tanto a una falta de interés, sino a las dificultades de obtener una información mínimamente consistente y fiable que permita avanzar sobre una cartografía financiera y las redes de flujos entre los espacios emisores y receptores de capital.

\section{Objetivos, planteamiento y metodología del trabajo}

Las recientes filtraciones publicadas por diversos medios sobre las redes societarias en paraísos fiscales permiten arrojar alguna luz sobre un asunto que, tradicionalmente, se ha mantenido prácticamente en el anonimato. Este trabajo tiene como objetivo ayudar a determinar algunos rasgos de la cartografía financiera europea y su relación con la estructura global de paraísos fiscales. Para su elaboración se ha tomado como referencia la base de datos relativa a Europa de los papeles de Panamá recogidos por el International Consortium of Investigative Journalists (ICI). La base de datos final cuenta con 11,5 millones de registros financieros de 785000 empresas de todo el mundo. En buena parte de ellas se ha podido obtener la localización exacta y el tipo de relación que las une, por lo que ha sido posible reconstruir la red espacial de relaciones entre sociedades financieras de toda Europa.

Las relaciones han sido obtenidas gracias al trabajo que numerosos colaboradores del ICI que han podido depurar y sistematizar la información obtenida. Esto supone una limitación evidente en la calidad de la misma, especialmente cuando la escala de análisis es local. En este punto hay numerosos registros que no han podido ser georreferenciados porque la dirección que figura no existe, o es ambigua. Sin embargo, los datos agrupados a escala regional o global sí parecen marcar una tendencia espacial muy determinada y es la que se pretende analizar en este trabajo. 
La propuesta de una cartografía financiera de Europa está basada en el análisis de la cadena de relaciones espaciales que se establece entre las diferentes sociedades que participan en la salida de capitales con destino a los centros financieros offshore (CFO). Se trata por tanto de localizar el lugar de residencia declarada de los propietarios de los activos, los puntos intermedios de paso y sus lugares de destino final.

Para analizar el comportamiento espacial de su cadena de dependencia jerárquica solo se han considerado aquellas relaciones donde se tiene constancia de la localización de las mismas en el espacio europeo. No es extraño así encontrar un elevado número de registros donde no se ha podido determinar con exactitud el país concreto en que se encuentra registrada una determinada sociedad.

Del mismo modo, su referencia está sujeta, tal y como advierten los responsables de su publicación, a un margen de error debido al enorme tamaño y las dificultades evidentes que tiene el esfuerzo de localizar y georreferenciar cientos de miles de sociedades de todo el mundo. Se trata por tanto de una fuente que no sigue los parámetros metodológicos de registros empresariales que pueden tener las fuentes estadísticas oficiales al uso.

Esto se debe en buena parte a que la base de datos analizada procede de miles de documentos, bases de datos, actas, pasaportes, correos electrónicos y cuentas bancarias depositadas en la firma de abogados Mossack-Fonseca durante casi cuarenta años. Los datos representan el conjunto de relaciones societarias desarrolladas a lo largo de décadas, por lo que numerosas sociedades y relaciones que figuran en este estudio no se han dado de forma simultánea. Un número importante de empresas se encuentran en situación de inactividad, se trata de sociedades instrumentales inertes, sin empleados ni centros de trabajo, que pueden reactivarse según el interés de las sociedades financieras que las controlan. No se trata por tanto de una radiografía de las relaciones financieras en distintos espacios y en un único momento, sino de la red generada a través de un proceso acumulado de varias décadas.

Otra limitación importante de esta fuente es que no está cuantificado el volumen de capital que se mueve a través de sus relaciones. Esto supone que la existencia de una interconexión entre sociedades de dos países no significa necesariamente que esté activa o que genere una transacción financiera determinada. Dicho de otro modo, pueden existir miles de relaciones financieras entre la isla de Jersey y Hong Kong, pero puede ser posible que el volumen de capital transferido entre ellas haya sido mínimo o lleven años inactivas, y un único depósito entre Suiza y Andorra haya supuesto un impacto mucho mayor que la suma de los anteriores. No se puede por tanto confundir el número de conexiones con el volumen de transacciones financieras. Esto supone una limitación a la hora de cuantificar los flujos económicos de capital entre espacios, pero no en 
cuanto a la estructura societaria de propiedad y dependencia, que es el punto fuerte de esta información.

La depuración de la información publicada ha sido adaptada a las necesidades de una investigación de carácter territorial. El primer paso ha sido seleccionar la escala de análisis. Lo más habitual habría sido tomar como referencia la delimitación correspondiente a la Unión Europea. Sin embargo, no ha sido considerado adecuado porque, entre otros motivos de peso, excluye algunos países como es el caso de Suiza, que juega un papel clave en la estructura financiera espacial mundial y por supuesto europea.

Desde el punto de vista de la organización geográfica, se ha tomado como referencia de estudio los límites tradicionales del continente europeo (incluido Rusia, que concentra la mayor parte de su estructura financiera al oeste de los Urales), al que se ha sumado aquellos espacios diseminados por el resto del mundo, especialmente a lo largo del Caribe y el Pacífico, que forman parte de la estructura política de la UE o tienen con ella una estrecha relación, aunque no se localicen en el interior del continente.

La consideración de este espacio financiero de influencia europea es capital para comprender las relaciones espaciales internas y entre regiones. En efecto, la compleja organización política del territorio de la UE, que abarca desde el continente americano hasta el Pacífico, se ha convertido en una red espacial clave para explicar la lógica interna de los movimientos de capital y su conjunto de relaciones societarias. Por ello, se ha optado por establecer cinco grandes regiones financieras en el interior del espacio geoeconómico europeo.

El primer territorio está formado por los 28 países de la UE, excluidos aquellos espacios asociados y territorios de ultramar. Es el corazón político, cultural, económico y territorial de Europa y, como veremos más adelante, un espacio económico de referencia global en torno al cual se articula y depende toda la estructura espacial de sociedades financieras.

Junto al caso anterior, se han delimitado dos zonas financieras diferenciadas: los espacios o países dependientes, autónomos y territorios asociados (DAA) y los países y territorios de ultramar (PTU). Se trata en ambos casos de zonas con un peso demográfico o económico residual en el contexto de Europa, pero ocupan una posición central en la red de relaciones financieras transnacionales. A las garantías de estabilidad geopolítica derivadas de su pertenencia a la UE, se une la excepcionalidad en el cumplimiento del acervo comunitario a través de una normativa singular, que va a ser utilizada para la evasión de capital procedente de Europa, así como otros movimientos de dudosa legalidad.

En el caso de los DAA, se trata de micro estados o espacios con distinto nivel de independencia legal con respecto a alguno de los 28 Estados de la UE. Tienen como elemento común una legislación mercantil y fiscal más favorable, lo que les convierte en un importante punto de paso de 
los activos financieros al exterior. Se localizan principalmente en el interior del continente europeo y las islas del Canal. ${ }^{1}$

El espacio financiero de los PTU está compuesto en su mayor parte por los restos coloniales del antiguo imperio británico, y es utilizado en numerosas ocasiones como paraísos fiscales controlados por Reino Unido. Se localiza fundamentalmente en dos grandes zonas: el Caribe y las pequeñas islas del Pacífico, y como veremos más adelante supone un importante nodo global de interconexiones financieras. $^{2}$

Esta clasificación supone una ruptura interna de las relaciones financieras del Reino Unido en tres grandes espacios funcionales interdependientes. El primero de ellos corresponde a las sociedades localizadas en Gran Bretaña e Irlanda, y que se contabiliza en el grupo de los países de la UE. El segundo es el territorio correspondiente a las Islas del Canal y de Man que se ha asociado al espacio DAA y por último los paraísos fiscales caribeños y del Pacífico, como el caso de las Islas Vírgenes Británicas, asignados al territorio PTU. ${ }^{3}$

Desde un punto de vista ortodoxo, puede resultar problemático realizar esta fragmentación de las sociedades de un Estado en distintos territorios, ya que infravalora de manera sensible el peso específico de los países de la UE al contabilizar los datos del Reino Unido en diferentes grupos. Siendo conscientes de ello, esta alternativa ofrece mejores posibilidades. En primer lugar se aprovecha la oportunidad de poder analizar la movilidad interna entre territorios de la red financiera del Reino Unido, y las ventajas que obtiene estando sujetas a diferente legislación. En segundo lugar permite mejorar la comprensión en el conocimiento de la influencia financiera europea fuera de sus límites continentales, pero dentro de su espacio de influencia geopolítica.

En ocasiones se percibe a los centros financieros offshore como pequeñas islas políticamente independientes, que constituyen un refugio seguro de activos procedentes de todo el mundo. Sin embargo conviene recordar que una parte muy importante de la red de paraísos fiscales caribeños se encuentra dentro de la UE, y cuenta con su protección política, militar y jurídica, al igual que ocurre por ejemplo en Estados Unidos con los Estados de Nevada o Wisconsin. Su ventaja competitiva con respecto a otros paraísos fiscales es precisamente la garantía de pertenecer a un espacio político de primer orden como es la UE, junto a las oportunidades derivadas de una

1 Andorra, Gibraltar, Isla de Man, Islas del Canal (Jersey y Guersney), Liechtenstein, Mónaco y San Marino.

2 Anguila, Aruba, Bermudas, Curazao, Guayana Francesa, Groenlandia, Islas BES, Islas Caimán, Islas Georgias del Sur y Sandwich del Sur, Islas Malvinas, Islas Pitcairn, Islas Turcas y Caicos, Islas Vírgenes Británicas, Martinica, Montserrat, Nueva Caledonia, Polinesia Francesa, San Bartolomé, San Pedro y Miquelón, Santa Elena, Ascensión y Tristán de Acuña, San Martín, Territorio Británico del Océano Índico, Tierras Australes Francesas y Wallis y Futuna. La información de Azores, Canarias, Madeira y los departamentos franceses de ultramar (con excepción de Guayana Francesa) no están desagregados por lo que sus datos forman parte de la UE-28.

3 Lo mismo ocurre con algunos espacios coloniales holandeses y franceses especialmente Curazao, Guayana y Polinesia Francesa, aunque con menor peso específico que los casos anteriores. 
legislación diferente que le permite realizar transacciones y depósitos financieros garantizando el secreto bancario, algo inviable en el resto de la UE. Se trata de una "Unión Europea offshore", un patio trasero de las finanzas en Europa, capaz de conjugar en un mismo territorio ambas ventajas comparativas con respecto a otros paraísos fiscales independientes.

En cuarto lugar, Suiza constituye un caso excepcional en los movimientos financieros europeos. Como veremos más adelante, desempeña un papel especialmente importante en la red espacial desarrollada en el interior del continente, así como una elevada proyección hacia otros centros financieros mundiales.

La quinta y última zona se corresponde con aquellos Estados del Norte y Oeste del continente que no pertenecen a la UE. ${ }^{4}$ En este caso Rusia es con diferencia el país con mayor influencia y conexiones financieras internacionales y lidera su propio espacio de influencia geoeconómica que alcanza hasta los países de Asia Central.

\section{Conexiones espaciales en Europa entre propietarios del capital, intermediarios y sociedades de destino en paraísos fiscales}

Con objeto de poder cuantificar la magnitud de las redes entre espacios, se ha tomado como referencia el concepto de conexiones financieras internacionales. Se define como una relación básica que existe entre dos sociedades en dos países distintos. Su nexo de unión se establece a través de la propiedad, la existencia de accionistas, testaferros u otras figuras que ponen a ambas empresas en relación en dos territorios diferentes.

La base de datos publicada por el ICI revela la existencia de 1,3 millones de conexiones financieras internacionales. Se han filtrado aquellas que tienen como origen o destino Europa, y de ellas se han eliminado aquellas que se dan en el interior de un mismo país o donde se desconoce su localización exacta. El resultado final revela la existencia de 235076 relaciones detectadas entre propietarios, intermediarios y entidades de depósito que tienen su origen en Europa. El número de relaciones de sociedades de todo el mundo con destino Europa es de 382 370, aunque la mayor parte de las mismas corresponde a empresas localizadas en las Islas Vírgenes Británicas, contabilizadas dentro del espacio de influencia geoeconómico y político europeo.

Existen numerosas conexiones que corresponden a una misma empresa financiera localizada en territorio europeo y que cuenta con una red diversificada de la que dependen numerosas sociedades offshore localizadas en varios paraísos fiscales. Se han contabilizado 205878

4 Albania, Bielorrusia, Islandia, Serbia (incluido Kosovo), Macedonia, Montenegro, Noruega, Rusia, Serbia y Ucrania (incluida Crimea). 
relaciones donde se sabe con exactitud que su origen es Europa y tienen un destino georreferenciado. ${ }^{5}$

Algunos autores han planteado recientemente un esquema aún muy básico de funcionamiento de los circuitos financieros espaciales, identificando un primer nivel de especialización entre lo que ellos denominan centros financieros offshore que funcionan como "conductos", espacios de tránsito el capital, y centros que lo hacen como "sumideros", es decir, los puntos de destino final de los activos (García-Bernardo, Fichtner, Toma \& Heemskerk, 2017). La cadena de circulación entre países que ha sido analizada según los flujos de inversión extranjera directa coincide en su morfología de forma similar al caso español (Autor, 2015). En ambos trabajos, la estructura organizativa de la red fiscal pone de manifiesto la existencia de un primer conjunto de países especializados en la circulación de capital y un segundo grupo de espacios de destino final. Los datos analizados por García-Bernardo identifican un total de 24 CFO que han denominado como "sumideros", y cinco países que funcionan como "conductos" especializados en las transferencias transnacionales de capital (Países Bajos, Reino Unido, Irlanda, Singapur y Suiza). Lo interesante en ambos casos es que aunque los datos analizados son diferentes la idea es la misma. Los conceptos de espacio emisor, intermediario y receptor coinciden aunque la denominación y la forma de tratarlos ha sido diferente.

Los datos filtrados en los denominados "papeles de Panamá" revelan la existencia de una tupida red interna origen-destino de conexiones entre sociedades localizadas en el interior de Europa. Tres cuartas partes de todas las relaciones financieras que tienen como origen Europa se dirigen hacia dos paraísos fiscales: Islas Vírgenes Británicas (64,5\%) y Panamá (13,8 \%). Junto a estos hay otros centros de menor rango, como es el caso de Bahamas (8,2\%), Seychelles (6,8 \%) y Niue (3,0 \%). El 66,0\% de todas las relaciones financieras de origen europeo se dirigen a espacios europeos de ultramar, por lo que la estructura organizativa de los flujos de capital parece buscar la garantía de estabilidad geopolítica que ofrece la pertenencia a la UE. En ellos coexisten por un lado las ventajas que ofrece la cohesión políica y por otro lado la opacidad legal que permiten las "especiales" condiciones de los espacios dependientes y ultra periféricos.

Es importante advertir que existe un sesgo en los patrones de localización derivados de la fuente de datos. El despacho panameño Mossack-Fonseca tiene su espacio de influencia en las Antillas y su cartera de clientes no está repartida de forma homogénea, sino se concentran en determinados países. Esto explicaría la baja representación de países de primer orden en la red, como es el caso de Francia, Alemania y Países Bajos donde el número de relaciones que figuran en los archivos publicados posiblemente estén muy por debajo de las cifras reales. No se trata por tanto que los

5 La diferencia es debida a que se han suprimido en el análisis aquellas sociedades adscritas de manera simultánea a varios países o con una localización confusa. 
residentes en estos países no evadan impuestos, sino que lo realizan a través de otras sociedades diferentes.

Los movimientos espaciales de capital tienen su máximo exponente en Reino Unido. En este caso ingentes flujos de capital no cambian de país, pero sí se desplazan miles de kilómetros de Europa al Caribe. Es indudable que la capacidad del Reino Unido en mantener una importante red de espacios por todo el mundo le proporciona una ventaja competitiva sustancial con respecto a otros centros financieros internacionales. Los datos analizados han permitido identificar la existencia de 370000 conexiones entre distintos puntos del mundo y las sociedades localizadas en las Islas Vírgenes Británicas. Un tercio de ellas procede de Hong Kong y China en un eje financiero Mar de la China-Caribe, que moviliza un ingente tráfico de capital financiero mundial. No obstante, los movimientos internos de la red británica con las Islas Vírgenes Británicas son considerables, ya que se han detectado cerca de 24000 conexiones con Jersey, 10400 con Guernsey, 6000 con la isla de Man y 12400 con Gran Bretaña e Irlanda del Norte.

Es probable que el Brexit pueda cambiar esta situación al limitar la capacidad de interconexión entre la red financiera británica y la de los grandes países de la UE. Aunque las incógnitas de este proceso son aún elevadas, la salida del Reino Unido de la UE puede favorecer la aparición de otros espacios financieros que suplan la función que en la actualidad ejercen los paraísos fiscales británicos.

Desde el punto de vista de la tipología de relaciones societarias, un 64,7\% de las conexiones entre sociedades financieras europeas y paraísos fiscales están basadas en términos de intermediación. Se trata por regla general de empresas pantalla localizadas en numerosos paraísos fiscales, y que funcionan como meros instrumentos dependientes de las localizadas en Europa. Estas son las que a la postre controlan los flujos de capital y tienen capacidad de decisión. El mismo ocurre con los accionistas, que representan el 32,3\% de las relaciones. El resto de la tipología de dependencia legal -nominee, beneficiarios, etc. - tienen una presencia muy residual.

No obstante, la situación es distinta cuando se desciende en la escala espacial de análisis. En el caso de los beneficiarios de fideicomisos, que apenas representan un 1,8\% de todas las relaciones societarias europeas, suponen un $22,6 \%$ en Malta. Lo mismo ocurre con conexiones de origen Europa y destino Nueva Zelanda (21,7\%); Belice (21,0 \%); Islas Cook (20,4 \%) y Chipre $(20,1 \%)$. A falta de un estudio más exhaustivo de estos casos, todo parece indicar que son espacios que tienen un elevado nivel de especialización en determinados productos de gestión de activos que favorecen la localización de este tipo de figuras. Esto les permite realizar transacciones financieras en términos más favorables para el beneficiario.

Es el caso por ejemplo de las denominadas fundaciones multimodales. Se trata de un instrumento financiero específico desarrollado en la isla de Las Nieves, donde no es necesario identificar a los 
beneficiarios, y por tanto refuerza el secreto de los depósitos. Los CFO son altamente competitivos y en muchos casos la estrategia de crecimiento se basa en una especialización en determinados productos del mercado financiero.

La estructura organizativa de los centros financieros en Europa presenta algunas características singulares en lo que respecta a sus pautas de localización. Las necesidades de una garantía jurídica de los depósitos, unida entre otros factores al secreto bancario o a la estabilidad política del CFO, son algunos de los elementos que explican una configuración espacial a medida de sus necesidades.

La Tabla 1 representa la localización de sociedades y personas europeas que tienen capital o intereses en paraísos fiscales. En algunos casos figura el denominado "beneficial owner", el verdadero dueño de la sociedad en torno al cual se construye la red de empresas y testaferros que ocultan su identidad. Junto a esta figura, aparecen también numerosos individuos imposibles de identificar al tratarse de acciones al portador (bearer shares) y accionistas nominales sin poder de control real (nominee shareholder).

Los datos analizados ponen de manifiesto una relativa sorpresa en su distribución espacial, ya que aquellos localizados dentro de la UE-28 apenas suponen un 29,05\% del total, una cifra sensiblemente inferior a la esperada, dadas las enormes diferencias demográficas y de PIB que representa este conjunto con respecto al resto de las zonas.

El territorio más destacado, que absorbe casi un tercio de los lugares nominales de residencia, corresponde a espacios dependientes, autónomos y asociados (DAA), el territorio donde se encuentra localizada la mayor parte de la estructura financiera británica, especialmente las Islas de Canal y Gibraltar junto a Andorra, Mónaco o San Marino entre otros.

\section{Tabla 1. Conexiones espaciales de grandes fortunas y sociedades financieras europeas con paraísos fiscales}

\begin{tabular}{|l|r|r|}
\hline Origen & Relaciones financieras & \multicolumn{1}{c|}{$\%$} \\
\hline Dependientes, autónomos y asociados (DAA) & 64764 & 31,5 \\
\hline Países UE-28 (excepto PTU y DAA) & 59802 & 29,0 \\
\hline Suiza & 39268 & 19,1 \\
\hline Países y territorios ultramar (PTU) & 32467 & 15,7 \\
\hline Norte y Europa Oriental no UE & 9576 & 4,7 \\
\hline Total & 205877 & 100,00 \\
\hline
\end{tabular}

Fuente: elaboración propia a partir de Papeles de Panamá (ICI, 2016) 
Los datos filtrados por la ICIJ ponen también en cuestión algunas ideas asentadas sobre Europa como un centro exclusivo de salida de capital hacia paraísos fiscales no europeos. El esquema de relaciones societarias demuestra que las interconexiones espaciales de la red financiera europea se realizan en buena parte en el interior de su territorio de influencia geoeconómica, aprovechando las ventajas fiscales de los espacios PTU y DAA. Incluso podría decirse que es más bien al contrario, el espacio geopolítico europeo es un territorio de captación de capital exterior, al menos de interconexiones financieras, con respecto a numerosos países de América y del Sudeste Asiático (Figura 1).

La cartografía revela que la mayor parte de las conexiones financieras de todo el mundo que tienen como destino Europa (incluido su espacio de influencia antillano) proceden principalmente del Reino Unido, China, Hong Kong y Taiwán. Rusia y Estados Unidos estarían en un segundo grupo aunque con menor peso específico que el anterior. En cualquier caso, la presencia de intereses financieros en el espacio geoeconómico europeo es global, ya que abarca prácticamente a todos los países del mundo.

La Figura 2 pone de manifiesto el elevado nivel de interdependencia existente entre los espacios financieros asiático y europeo. Existe una concentración de interconexiones entre sociedades financieras procedentes de Hong Kong, China continental, Taiwán o Singapur con empresas europeas, principalmente localizadas en Reino Unido a través de su colonia de las Islas Vírgenes. A falta de conocer las conexiones financieras con sociedades de Estados Unidos, que tienen una baja representación en la base de datos publicada por el ICI, todo parece apuntar a que el eje China continental-Hong Kong con Reino Unido es uno de los más importantes del mundo, al menos en lo que respecta a la red societaria de evasión fiscal a CFO.

Figura 1. Conexiones financieras internacionales con destino Europa

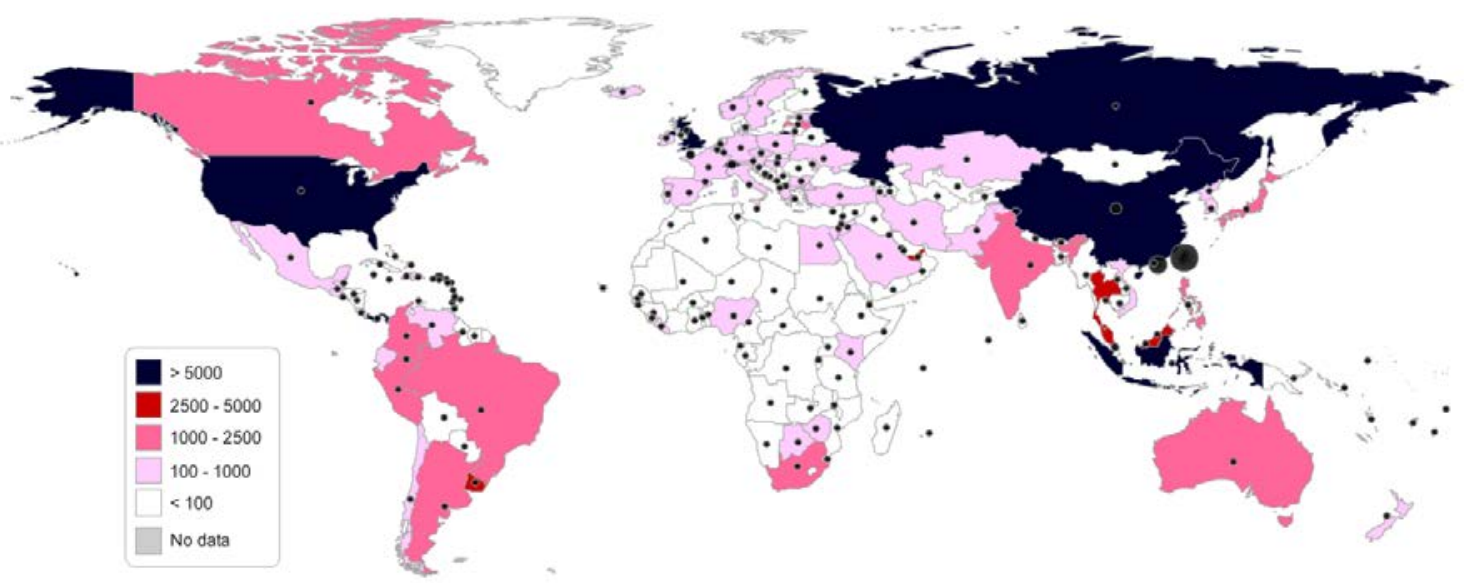

Fuente: elaboración propia a partir de Papeles de Panamá (ICIJ, 2016) 
Figura 2. Conexiones financieras del sudeste asiático con destino Europa

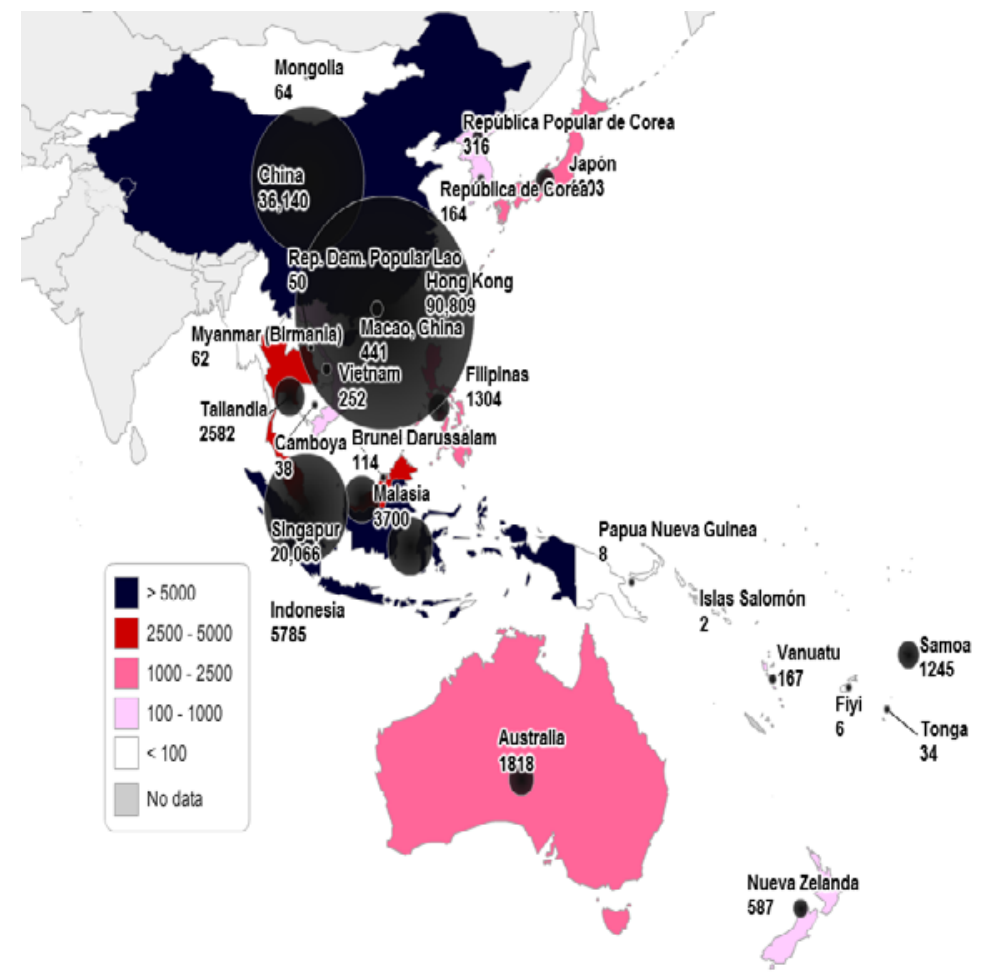

Fuente: elaboración propia a partir de Papeles de Panamá (ICII, 2016)

Desde una perspectiva geopolítica, la capacidad de atracción no solo corresponde a su espacio natural de influencia, sino que se han detectado relaciones entre sociedades financieras europeas y países con tensiones políiticas nacionales o internacionales, como es el caso de Corea del Norte, Irán o Venezuela. Todos los intereses financieros de estos países se localizan en las Islas Vírgenes Británicas, con excepción de algunos casos testimoniales situados en Anguila.

Desde un punto de vista geopolítico, se han identificado un mayor número de relaciones financieras entre personas y sociedades de Corea del Norte (316) que en Corea del Sur (164). EL ICI advierte de la existencia de posibles errores en la localización de sociedades y que algunos datos georreferenciados hay que tomarlos con precaución. Algunas sociedades surcoreanas, como es el caso de Hyundai Merchant Marine que se encuentra registrada en Corea del Norte, podrían ser debidas a errores en la localización exacta de los registros o bien que en efecto se encuentre situada una filial de la multinacional en el complejo norcoreano de Kaesong.

La mayor parte de las conexiones financieras registradas en Corea del Norte corresponden a particulares y no a sociedades, como ocurre en el resto del mundo. Existen algunas sospechas sobre el uso de la estructura financiera panameña para respaldar el programa nuclear norcoreano. Es el caso de un ciudadano norcoreano, accionista del DCB Finance Limited, una filial del Daedong Credit Bank, el primer banco de Corea del Norte y sancionado en 2013 por el Tesoro de Estados Unidos por financiar un programa de armas de destrucción masiva. Esta persona se encuentra 
registrada en la Casa Internacional de Cultura de Pyongyang, sin embargo la información de localización proporcionada por la propia ICIJ está referenciada en Irán.

En el caso iraní, se ha podido localizar el origen y destino de 119 conexiones financieras, todas ellas en sociedades de las Islas Vírgenes. Algunas de ellas están relacionadas con empresas energéticas, como es el caso de Petropars Limited y Petrochemical Industries Investment Co., que tienen sociedades registradas en Irán y filiales en las propias Islas. En Venezuela se han registrado 865 relaciones con sociedades, la mayor parte de ellas localizadas en las Islas Vírgenes. Se trata de particulares y una reducida presencia de sociedades limitada a despachos de abogados y consultoras que ejercen de intermediarios.

Las implicaciones políticas concretas de las personas que aparecen en los papeles de Panamá están siendo desarrollados por decenas de publicaciones de todo tipo y no son objetivo de este trabajo. No obstante sí parece interesante poner de manifiesto que la existencia de esta red financiera internacional no solo obedece a actividades ilícitas como ocultación de patrimonio, evasión fiscal u obtención ilícita de activos ligados a casos de corrupción. Las repercusiones de esta red, donde países con elevado nivel de conflicto geopolítico tienen intereses en sociedades europeas ligadas principalmente a capital británico, pone de manifiesto la complejidad de este tipo de relaciones donde no siempre están claras las posiciones políticas de los actores implicados. Las grandes sociedades financieras internacionales, son las que en última instancia han diseñado una red que puede tener una importante capacidad de influencia en la política interna de determinados Estados que tienen dificultades de captación de capital en los mercados internacionales.

El corazón de esta "Europa offshore" se encuentra articulado en torno a la red financiera británica, por donde circula la mayor parte de las conexiones hacia paraísos fiscales entre Europa y el exterior. Hay que entender que Reino Unido cuenta con numerosos espacios de excepcionalidad fiscal (Jersey, Guernsey, Islas Vírgenes, etc.), que se articulan jurídicamente entre otras a través de la Ley de "Controlled Foreign Companies" (CFCs) dirigida básicamente a desincentivar la evasión fiscal de las sociedades domiciliadas en Reino Unido y regular las empresas del exterior (Gutiérrez de Pablo, 2015). La especialización fiscal de esta red permite dirigir flujos de capital desde las empresas y grandes fortunas, con destino a numerosas sociedades de las islas del Canal y las posesiones británicas en el cinturón de las Antillas.

La red jurídica de relaciones entre los territorios dependientes de la Corona Británica es compleja y su análisis desviaría el objetivo de este trabajo. No obstante es importante saber que existe una cierta especialización legal de cada espacio en productos financieros, y una tipología de sociedades que define la circulación del capital entre espacios. No parece al menos a priori que las iniciativas comunitarias en materia de regulación en la evasión fiscal estén dando los resultados esperados. Quizás la más destacada es el Common Reporting Standard (CRS). Se trata de una 
versión europea del Foreign Account Tax Compliance Act (FATCA) de Estados Unidos, promovida por el G-20 e implementada por la OCDE y la UE. Consiste en un sistema de intercambio automático de información entre países, articulado en la UE a través de la Directiva 107/2014/UE que, al menos sobre el papel, permite conocer a cada país miembro los movimientos transnacionales de capital.

Los instrumentos de evasión fiscal de planifican a través de los denominados BEPS. Se trata de un conjunto de estrategias, denominadas por la OCDE como "erosión de base imponible" y que en realidad consisten en un mecanismo organizado para evitar pagar impuestos. Se trata de encontrar resquicios legales en la normativa sobre regulación de flujos financieros transfronterizos a través de los cuales los movimientos de capital entre las distintas sociedades de las empresas multinacionales, provocan que no se paguen impuestos en ninguno de los países donde tributan, o que estos sean muy reducidos. Un reciente estudio de Los Verdes en la Comisión Europea señala que el Gran Ducado de Luxemburgo evitó entre 2005 y 2016 ingresos fiscales por valor de 317 millones de euros en el conjunto de sociedades que figura en los papeles de Panamá. La hacienda alemana, británica y belga serían las más afectadas. No obstante, se trata de una cifra irrisoria muy por debajo de datos más realistas (Giegold, 2017).

La creación de sociedades ad hoc para la evasión fiscal, como son las Compañías Internacionales de Negocios" (IBC) de las Islas Vírgenes Británicas, permiten emitir acciones al portador y no identificar en registro alguno a sus propietarios, excepto en la investigación penal. En el caso de Gibraltar, el "Income Gibraltar Act 2010" permite tributar el Impuesto de Sociedades al 10\%, frente al 30\% de las empresas españolas localizadas al otro lado del Peñón. En Guernsey, algunas sociedades offshore están exentas de impuestos si cumplen determinados requisitos. Desde Jersey operan numerosas empresas y trust aprovechando que determinados regímenes tributarios se encuentran exentos de IVA. Santander, ABN AMRO, Bank of India o BNP Paribas son solo algunos de los centenares de bancos que tienen filiales en la isla.

\subsection{El caso de la Unión Europea}

Uno de los elementos más llamativos en la morfología de la red financiera analizada es el papel que desempeña dentro de la UE. Veremos más adelante cómo parece existir varios espacios financieros bien diferenciados en cuanto a su funcionalidad y la jerarquía que ocupa con respecto a la UE este conglomerado de islas, dependencias, territorios autónomos, con todo tipo de relaciones, de esta "UE offshore". El centro de gravedad de las relaciones financieras se concentra en este pequeño pero poderoso espacio, que absorbe un 58,8 \% de todas las interconexiones de Europa. Los países de la UE utilizan de forma política y fiscal esta red que externalizar los beneficios que las grandes empresas y residentes obtienen en su interior. 
Sin embargo, la situación es diferente cuando se analiza la composición financiera existente en el interior "no offshore" de la UE. En este caso, la concentración espacial de estas sociedades es aún mayor cuando se analiza la distribución por países. A pesar de haberse contabilizado en otros espacios toda la cadena de dependencia financiera británica, el 72,5\% de todas las relaciones tienen su origen en solo tres países: Reino Unido, Luxemburgo y Chipre. España, el cuarto país y a una gran distancia de los anteriores es el origen de 2012 relaciones, que apenas representan un 3,4 \% del total. Más de la mitad de las conexiones con origen en la UE e intermediarios en las Islas del Canal tienen como destino las Islas Vírgenes Británicas, que junto a Bahamas y Seychelles representan el 73,6\% de las relaciones con el exterior.

Quince de los veintiocho países miembros de la UE absorben menos de un $1 \%$ de las interconexiones, y grandes potencias económicas como Alemania o Francia ocupan una posición marginal en la red. Tal vez sea plausible pensar que el propio origen de los datos, determinado por los clientes con los que ha trabajado Mossack-Fonseca durante cuatro décadas, es clave para explicar esta cuestión. Las grandes fortunas alemanas o francesas estarían vinculadas con otros despachos financieros por lo que su peso específico en los datos aquí analizados es menor.

Resulta cuanto menos llamativo que la UE ha publicado una lista con 17 jurisdicciones no cooperativas, es decir paraísos fiscales. ${ }^{6}$ Sin embargo, ninguno de ellos corresponde a un espacio de influencia o pertenencia a la propia UE. En la relación de 47 territorios "grises" que se han comprometido a realizar reformas legislativas no aparecen por ningún lado las Islas Vírgenes Británicas, Malta, Chipre o Luxemburgo. La ambigüedad calculada de la UE en materia de controles de flujos transnacionales y la catalogación selectiva de paraísos fiscales pone de manifiesto que estos son utilizados políticamente por los estados miembros de forma generalizada para dar cobertura a la evasión de beneficios empresariales y omisión de los deberes fiscales de las grandes fortunas. ${ }^{7}$ La capacidad de bloqueo sistemático de cualquier medida política por parte de algunos Estados como Malta, Chipre, Irlanda, Luxemburgo, Reino Unido o Países Bajos no puede ser un obstáculo para realizar avances sustanciales en materia de regulación fiscal.

Una cuestión diferente son las pautas de localización que se dan en el interior del continente. El centro de gravedad de su cartografía financiera se centra en torno al eje Irlanda-Norte de Italia. Se trata de una gran región en forma de media luna que se inicia en Irlanda, continua por Londres, las islas del Canal, Luxemburgo, París, Estrasburgo, gran parte de la región de Baviera, Zúrich,

6 Bahréin, Barbados, Corea del Sur, Emiratos Árabes, Granada, Guam, Islas Marshall, Macao, Mongolia, Namibia, Palau, Panamá, Samoa, la Samoa Americana, Santa Lucía, Trinidad y Tobago y Túnez.

7 La denominada "lista gris" está compuesta por Albania, Andorra, Armenia, Aruba, Belice, Bermuda, Bosnia y Herzegovina, Botsuana, Cabo Verde, Islas Caimán, Islas Cook, Curazao, Islas Feroe, Fiyi, Macedonia, Groenlandia, Guernsey, Hong Kong, Isla de Man, Jamaica, Jersey, Jordania, Liechtenstein, Malasia y Labuan, Maldivas, Mauricio, Montenegro, Marruecos, Nauru, Nueva Caledonia, Niue, Perú, Omán, Qatar, San Vicente y las Granadinas, San Marino, Seychelles, Suiza, Serbia, Suazilandia, Taiwan, Tailandia, Turkquía, Uruguay y Vanuatu. 
Ginebra y finaliza en el norte de Italia. Es el epicentro de concentración financiera de Europa y en su centro de gravedad se localiza en el triángulo Reino Unido-Países Bajos-Luxemburgo. La estructura territorial de la localización financiera coincide, con excepciones, con la morfología urbana de cada país. Existe una elevada concentración de conexiones financieras en los centros más exclusivos de las grandes ciudades del Reino Unido, Francia, Países Bajos e Irlanda. Por el contrario, la densidad urbana es menor en Alemania, Suiza o España. En el caso de ltalia existe un claro contraste territorial entre el norte y el sur. El primero cuenta con una elevada presencia de grandes fortunas como una continuación natural de lo que ocurre en Francia o Suiza. Frente a ello, el sur de Italia cuenta con una densidad bastante menor (Figura 3).

Existe una segunda zona financiera costera de menor importancia que la anterior. Se inicia en el mar de Liguria y la Costa Azul francesa a lo largo del eje Génova-San Remo-Niza-Marsella. Continúa por una parte de la costa de España hasta alcanzar las playas del Algarve portugués. Coincide en general con lujosos espacios turístico-residenciales reservados mayoritariamente a las clases altas de la sociedad europea. Uno de los patrones característicos de los residentes con fondos declarados en paraísos fiscales es su tendencia a residir en los espacios más selectos de toda la costa europea.

Londres es sin duda el corazón financiero de Europa y la localización de las grandes fortunas se concentra en los mejores barrios de la ciudad, especialmente en los alrededores de Hyde Park. Chelsea, Kensington y por supuesto la City son otras de las zonas de residencia declarada por las grandes fortunas que cuentan con intereses en paraísos fiscales (Figura 4).

La enorme dispersión de puntos a lo largo de los planos de las grandes ciudades pone de manifiesto la intensidad del fenómeno de evasión fiscal, que no es exclusivo de un selecto grupo de personas de clase alta, sino que existen también numerosos ciudadanos de clase media alta que utilizan ingeniería financiera offshore para evadir impuestos u ocultar su patrimonio. Este fenómeno no es exclusivo de Europa, en el caso de las grandes metrópolis de América del Sur ciudadanos y empresas que tienen relación con sociedades en paraísos fiscales se localizan también en los barrios más selectos. 
Figura 3. Residencia declarada de ciudadanos y sociedades con intereses en paraísos fiscales en Europa Occidental

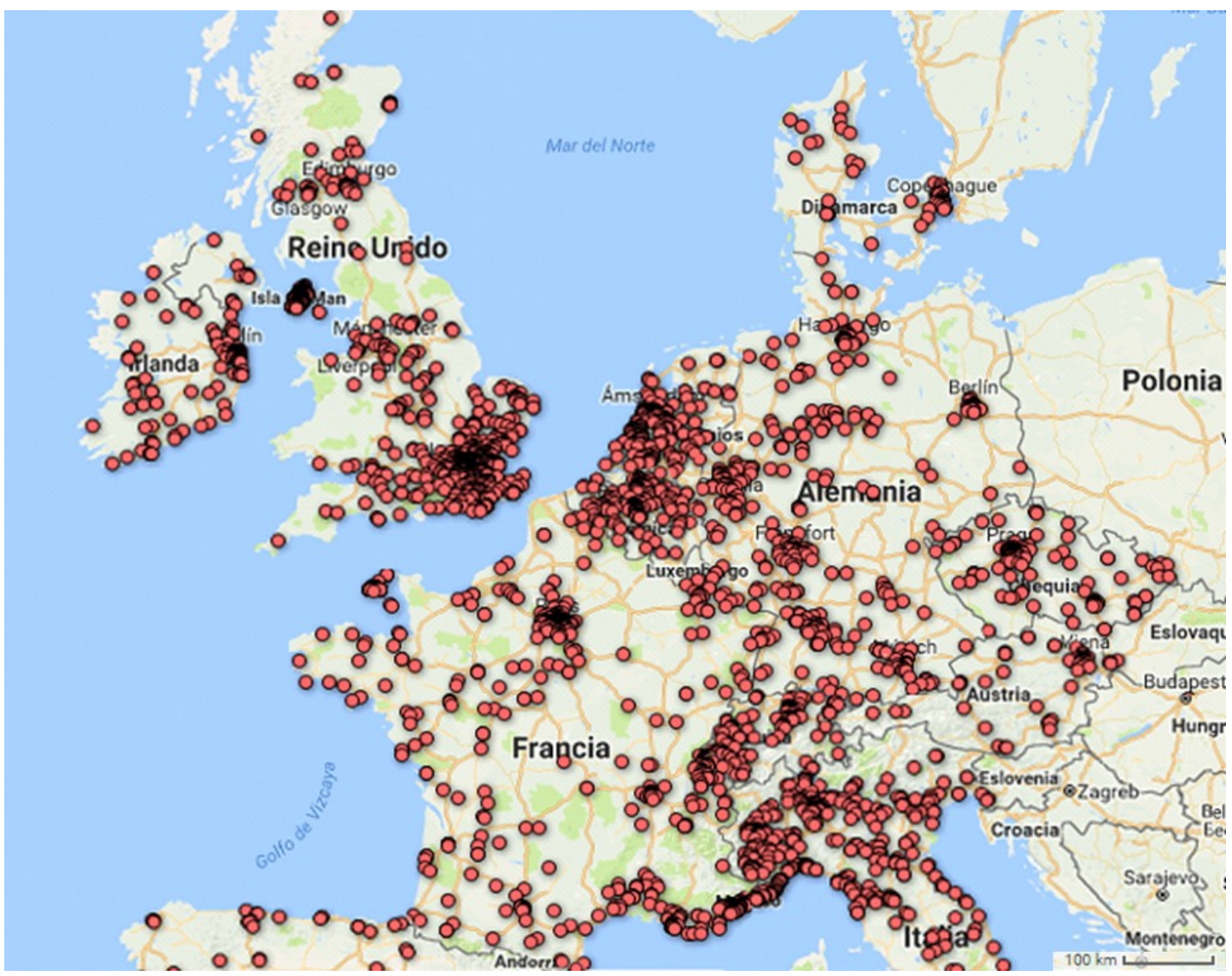

Fuente: elaboración propia a partir de Papeles de Panamá (ICI, 2016)

Figura 4. Localización de ciudadanos y sociedades en el centro de Londres con intereses en paraísos fiscales

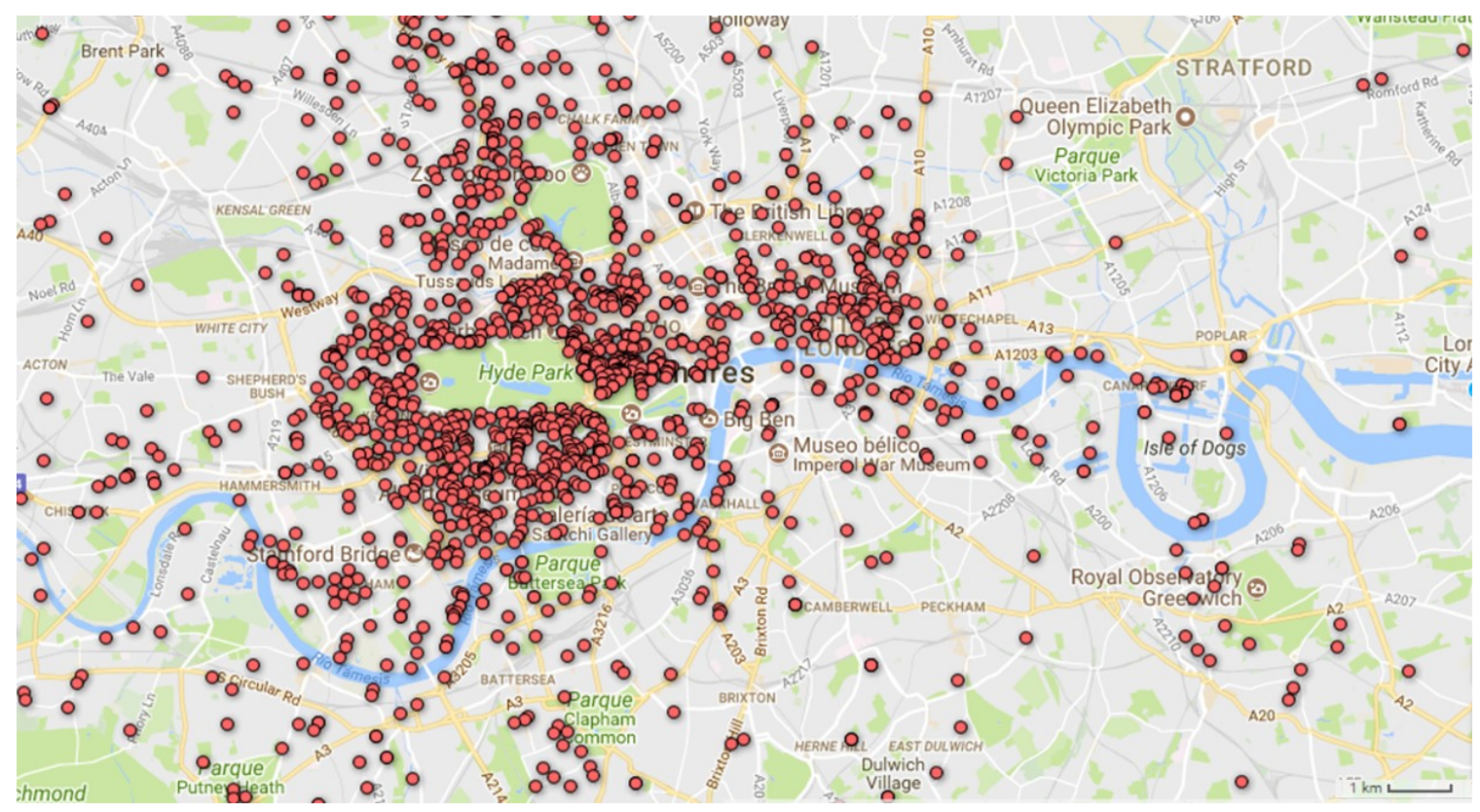

Fuente: elaboración propia a partir de Papeles de Panamá (ICIJ, 2016) 


\subsection{Territorios dependientes, autónomos y asociados (DAA)}

Se trata de apenas ocho pequeños estados, Andorra, Gibraltar, Guernsey, Man, Jersey, Liechtenstein, Mónaco y San Marino. No alcanzan en su conjunto el medio millón de habitantes, y representan nada menos que una tercera parte de las conexiones financieras con paraísos fiscales registradas en Europa, una relación por cada siete habitantes. Se trata de la mayor cifra absoluta y por supuesto relativa de toda Europa. Para hacerse una idea de su centralidad basta observar que los 28 países de la UE, con 508 millones de habitantes, no alcanzan las 60000 conexiones financieras. Es, junto al conglomerado financiero del río de la Perla, uno de los mayores del mundo.

Este conjunto de espacios está compuesto por un heterogéneo grupo de colonias, bailiazgos y micro estados localizados en el interior del continente. Sin embargo, comparten dos rasgos comunes. El primero de ellos es su tradición histórica como papel en los paraísos fiscales. Son los casos de Mónaco o San Marino, que se encuentran especializados en esta actividad desde comienzos del siglo XX y funcionan como espacios tradicionalmente receptores de impuestos evadidos por residentes de las grandes economías europeas.

El segundo rasgo característico es que cuentan con una protección geopolítica y una estructura legal específica con respecto a la normativa de la UE. Este último punto supone una ventaja fiscal competitiva en comparación con el núcleo de países de la UE-28 que explica al menos en parte, la elevada proporción de sociedades y ciudadanos allí registrados, así como el elevado número de interconexiones que generan, tanto en Europa como en el resto del mundo.

El 81,2\% de todas estas relaciones registradas en este espacio se concentra en las Islas del Canal y de Man (Figura 5). El principal eje de conexión financiera es totalmente británico, ya que se trata de intermediarios registrados en Jersey y Guernsey que controlan sociedades localizadas en las Islas Vírgenes Británicas, lugar de destino del 72,9\% de todas las relaciones financieras que tiene con el exterior. Está muy por encima del resto de destinos importantes como Panamá, Niue o la Seychelles que entre todos apenas representan un $14,2 \%$ de la red.

Simplificando la cartografía nodal, podría decirse que el principal canal financiero offshore de Europa comienza en sociedades del continente con sede en Londres. La intermediación corresponde a la filial de algún gran banco o servicio financiero de Jersey y finaliza en las Islas Vírgenes Británicas. Este eje vertebra una parte sustancial de las relaciones financieras internas de toda Europa. El dinero puede desplazarse miles de kilómetros con total garantía jurídica y seguridad geopolítica, ya que tanto los territorios de tránsito, como los sumideros están al amparo del control directo o indirecto de la propia UE, por lo que las posibilidades de inestabilidad política que ponga en riesgo la red de circulación del capital son escasas. 
Algunos autores como Zucman señalan que este circuito se cierra a través de reinversiones de los capitales depositados en paraísos fiscales en numerosos activos de todo el mundo, especialmente en el mercado inmobiliario británico. La circulación espacial de capital financiero es completa y constante, y sus parámetros de localización parece estar ligados a la búsqueda de oportunidades especulativas, bajo riesgo y garantía de anonimato (Zucman, 2014).

\section{Figura 5. Conexiones financieras internacionales con origen en el espacio DAA (2016, en miles)}

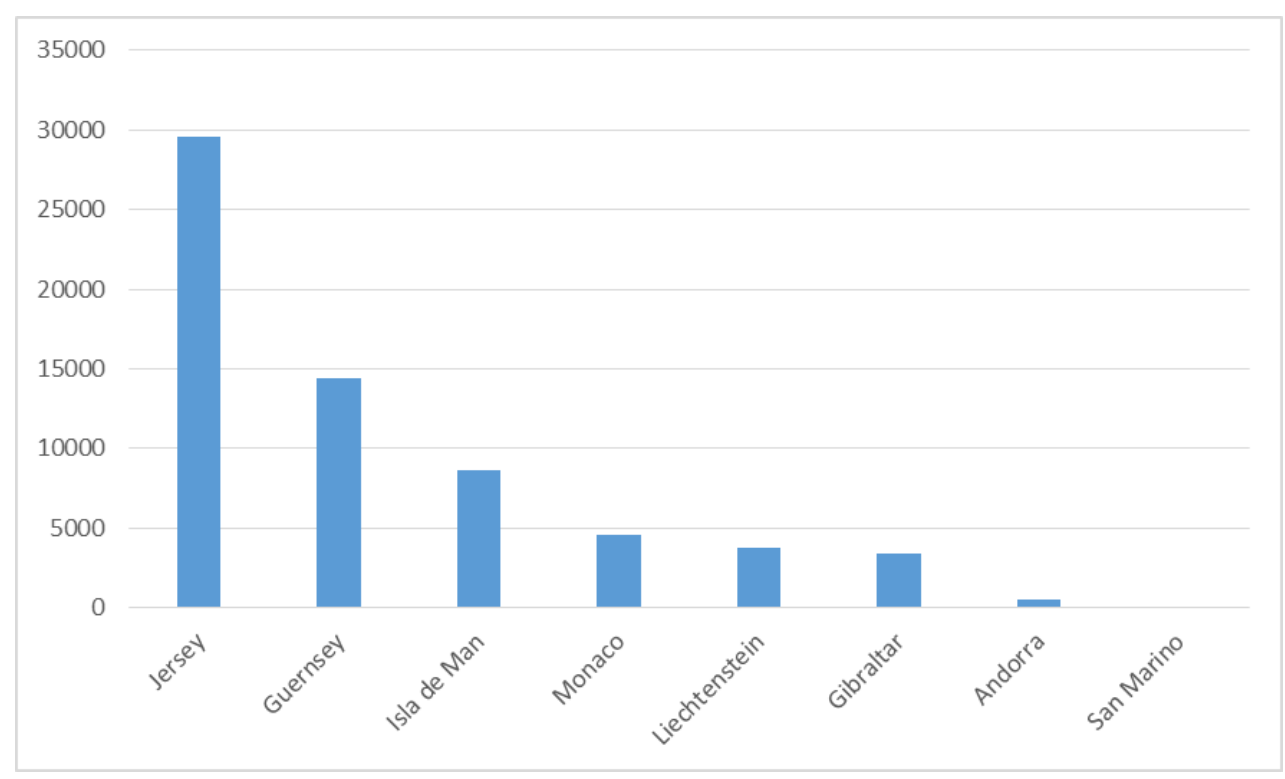

Fuente: elaboración propia a partir de Papeles de Panamá (ICIJ, 2016)

A pesar de que los datos publicados tienen una capacidad limitada en lo que respecta a la información de empresas determinadas, se ha detectado la existencia de una estructura fuertemente jerarquizada en torno a un reducido número de sociedades. Este conjunto de empresas globales cuentan con una red financiera altamente diversificada desde un punto de vista espacial, con múltiples sociedades filiales en distintos puntos del planeta que funcionan en forma de red. Así, las empresas con mayor número de relaciones espaciales coinciden con los grandes servicios financieros mundiales. La red con mayor nivel de diversificación es la de Credit Suisse Channel Islands Limited, con un mínimo de 918 conexiones contrastadas con otras sociedades en paraísos fiscales. Le siguen por orden de importancia HSBC Private Bank Monaco S.A. (777), Minerva Trust \& Corporate Services Limited (768), Nautilus Trust Company Limited (706), BOS Trust Company (Jersey) Limited (690), Charterhouse Lombard Limited Isle of Man (658) y Audina Treuhand AG (594). En su conjunto representan un 7,9\% de todas las conexiones registradas en este territorio.

La dimensión, estructura y morfología de esta red está condicionada por la cartera de clientes del despacho de abogados panameño. Es posible que otras sociedades financieras no utilicen las Islas 
Vírgenes como destino final, aunque es probable que los intermediarios se localicen en el mismo espacio dado su elevado nivel de centralidad y especialización.

\subsection{Países y territorios ultramar (PTU)}

Coincidente en su mayor parte con los paraísos fiscales caribeños y las islas del Pacífico, este espacio es un nudo estratégico de interconexiones financieras a escala internacional. El 66,1\% de todas las relaciones financieras de residentes europeos tiene como destino final este territorio. Fuera de este espacio, solo Chipre, Malta y Reino Unido tienen en Europa una presencia significativa como destino de conexiones financieras. Igualmente, apenas un $34 \%$ de las relaciones se establecen con territorios fuera del espacio de influencia política de la UE, y en ellos el peso de Panamá es de nuevo evidente por el propio origen de los datos (Tabla 2).

Tabla 2. Destino mundial de las conexiones financieras con origen en Europa

\begin{tabular}{|l|r|l|r|}
\hline Destino & $\begin{array}{r}\text { Relaciones } \\
\text { financieras }\end{array}$ & Destino & $\begin{array}{r}\text { Relaciones } \\
\text { financieras }\end{array}$ \\
\hline Islas Vírgenes Británicas (R. U.) & 132857 & Panamá & 28379 \\
\hline Islas Caimán (R. U.) & 1781 & Bahamas & 16897 \\
\hline Anguila Británica (R. U.) & 1363 & Seychelles & 13965 \\
\hline Bermudas & 3 & Niue & 6266 \\
\hline Total territorio PTU & 136004 & Samoa & 2133 \\
\hline & & Hong Kong & 480 \\
\hline & & Nevada (EE.UU.) & 430 \\
\hline & & Singapur & 300 \\
\hline Chipre & 172 & Islas Cook & 253 \\
\hline Reino Unido (resto) & 99 & Labuan & 237 \\
\hline Malta & 73 & Belice & 80 \\
\hline Irlanda & 5 & Wyoming (EE.UU.) & 26 \\
\hline Alemania & 1 & Nueva Zelanda & 23 \\
\hline Italia & 1 & Uruguay & 23 \\
\hline Bulgaria & 1 & Mauricio & 12 \\
\hline Total resto de Europa & 352 & Indonesia & 6 \\
\hline & & Costa Rica & 4 \\
\hline & & Malasia & 3 \\
\hline & & Ras al-Jaima (E.A.U.) & 3 \\
\hline Espacio geoeconómico europeo & 136356 & Otros espacios & 69521 \\
\hline & & Total & 205877 \\
\hline
\end{tabular}

Fuente: elaboración propia a partir de Papeles de Panamá (ICI, 2016)

La posición en el mapa europeo y mundial como zona receptora de capital se pone de manifiesto cuando se analiza el destino de las conexiones financieras de las Islas Vírgenes Británicas, su principal punto de referencia. Este es el destino final del 49,3\% de todas las conexiones mundiales donde se ha podido detectar su origen. Son cerca de 370000 relaciones con distintos países del mundo. Es de lejos el principal centro de atracción financiero de esta fuente de datos y está 
controlado indirectamente por la UE. La diversificación espacial de los activos depositados en las Islas Vírgenes es elevada, en la medida en que hay registrada la presencia de conexiones financieras procedentes de 45 países y numerosas colonias.

El número de relaciones que tiene como punto de origen el espacio PTU asciende a 32 467, la mayor parte de las cuales son internas, es decir, se producen entre ciudadanos y empresas instaladas dentro de su territorio y se encuentran articuladas en torno a las Islas Vírgenes Británicas que absorbe un $88,4 \%$ de los flujos especiales internos, seguida a distancia por Bermudas, Caimán y Panamá.

Su proyección se pone de manifiesto cuando se analiza el sentido de los flujos hacia otros espacios económicos (Figura 6). Tan solo un 18,1\% de las relaciones societarias de las Islas Vírgenes Británicas son internas, entre empresas o ciudadanos con domicilio declarado dentro de la Isla. El resto se dirige mayoritariamente al Reino Unido (eje Jersey-Guernsey-Gran Bretaña) y Suiza, que supone un $15,7 \%$ de las relaciones.

\section{Figura 6. Conexiones financieras de las Islas Vírgenes Británicas}

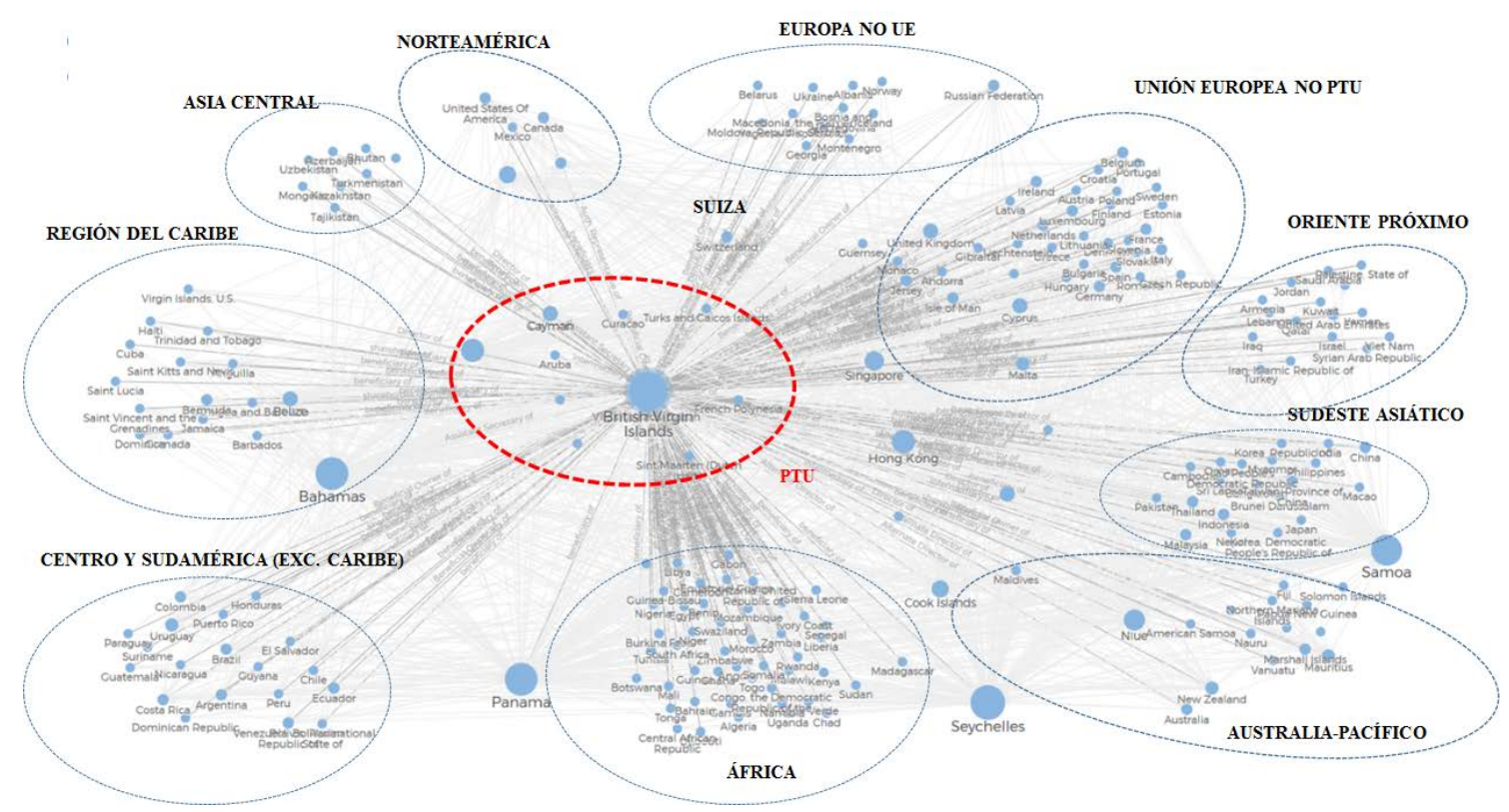

Fuente: elaboración propia a partir de Papeles de Panamá (ICI, 2016)

Teniendo esto en consideración, y con los datos disponibles en la actualidad, la cadena de propiedad de la estructura financiera europea finaliza en la isla. La capacidad de atracción del resto de CFO son testimoniales, excepto en los casos de Anguila Británica y las Caimán, aunque entre ambas apenas representan un 3,2\% de las conexiones de destino final. El sesgo de la información es de nuevo determinante para comprender este desequilibrio y por tanto no puede extrapolarse al comportamiento global de la totalidad de los mercados financieros internacionales hacia paraísos fiscales. 
El peso específico del circuito caribeño y su área de influencia (Aruba y Curazao) es bastante significativo, ya que el espacio financiero del Pacífico-Índico tiene una influencia residual. El eje Caribe-Pacífico tiene su origen en las Islas Vírgenes Británicas y su destino principal el eje SamoaSingapur, especialmente con las Islas Cook.

No hay duda que en términos generales el sentido de los flujos espaciales parte de los espacios centrales de las grandes economías hacia su periferia offshore, y el espacio PTU es el corazón de la misma al menos en Europa. Abundan ejemplos de ello como es el caso de Acticorp Limited. Se trata de la sociedad registrada que cuenta con mayor número de conexiones internacionales, con 1343 relaciones con sociedades localizadas principalmente en las Islas Vírgenes Británicas y que se encuentra inactiva en el momento de redactar este artículo. Alliance Corporate Services Limited, Burnham Limited o North Atlantic Service Limited, localizadas en Aruba, Caimán o Bermudas son otras entidades muy ramificadas que parecen funcionar como sociedad de referencia a terceras compañías.

Recientemente se ha realizado una operación de compra del "The Center", el edificio más caro del mundo, situado en pleno centro financiero de Hong Kong. Ha sido adquirido por CHMT Peaceful Development Asia Property Limited, una sociedad compuesta por China Energy Reserve \& Chemicals Group, con un 55 \% del capital, y un grupo de empresarios hongkoneses que cuenta con el $45 \%$ restante.

Lo interesante de la operación es que CHMT ha sido constituida en las Islas Vírgenes Británicas específicamente para realizar esta operación, y no en China como cabría esperar. Las conexiones financieras entre China y Reino Unido están de nuevo en el trasfondo de las grandes operaciones de compra-venta internacionales.

El volumen de capital que circula por esta región es importante. Algunos estudios determinan que el valor de los activos depositados en las Bahamas, Antillas Neerlandesas e Islas Caimán alcanza los dos billones de dólares. Esta última isla tiene el mayor sector bancario offshore en la región, con 900000 millones de dólares en activos depositados en los bancos en 2005 (Geamanu \& Dumitrana, 2015). Bermudas por su parte no cuenta con la banca offshore de las Caimán pero está especializada en seguros. El impacto que los servicios financieros tienen sobre las islas caribeñas es muy positiva, en la medida en que contribuye a dinamizar las economías de los países, aunque en algunas ocasiones se crea una dependencia absoluta con respecto a la economía y el turismo financiero. No obstante se advierte que la creciente competencia entre espacios offshore genera una revalorización de las relaciones institucionales y su reputación en el mercado financiero (Butkiewicz \& Gordon, 2013). Precisamente esta reputación y una creciente presión que numerosos organismos internacionales están ejerciendo sobre el espacio caribeño son elementos que amenazan a este territorio en relación con otros territorios offshore. 


\subsection{El singular caso suizo}

Suiza es el caso más significativo de todo este proceso. Los archivos publicados revelan la existencia en este país de 4594 officers, esto es, personas o sociedades que figuran como propietarias del capital. Existen en el país al menos 1339 intermediarios y 38077 entities, sociedades de destino, una parte importante de las cuales son shelf companies, sociedades in actividad que pueden ser compradas o vendidas en cualquier momento. Los datos reales son sin duda mucho mayores, pero esta parte de la información está identificada, y lo que es más importante, se puede determinar las relaciones espaciales con sociedades financieras de terceros países.

Los intermediarios constituyen en algunos casos sociedades que prestan servicios financieros altamente especializados en materia de deslocalización empresarial, transferencias internacionales de capital, traslados de residencia de los propietarios del capital, asistencia a la expansión geográfica o apertura de nuevos mercados entre otros. Se trata por tanto de empresas con elevados niveles de cualificación y conocedoras de las redes geográficas de conexiones para la transferencia de activos entre países. Su misión principal consiste en asesorar sobre las mejores oportunidades para transferir capital hacia aquellos espacios con menores o casi nulas cargas fiscales y que garanticen el estado de sus depósitos. Algunos autores señalan sin embargo que el verdadero interés de Suiza no reside tanto por su capacidad de intermediación, que puede realizarse a través de otros CFO, sino en su capacidad de garantizar el secreto bancario, permitiendo así ocultar quiénes son los verdaderos propietarios del capital. (Zucman, 2014).

En lo que respecta a su papel en Europa, Suiza es el origen del 19,1\% de las conexiones financieras europeas, y un $80,8 \%$ de las mismas se dirigen a dos únicos destinos: Islas Vírgenes Británicas $(53,3 \%)$ y Panamá $(27,5 \%)$. El resto se reparte entre un gran número de paraísos fiscales donde solo Seychelles y Niue tienen una presencia significativa, ya que representan entre ambas un $10,7 \%$.

Por lo tanto, la globalización financiera también tiene sus destinos principales y aunque las conexiones de Suiza con el exterior se dirigen hacia 20 países diferentes, nueve de cada diez lo hacen a estos cuatro Estados. Esto coincide con lo que ocurre en el resto de las regiones analizadas, donde la multiplicidad de destinos y el número de países implicados en los mismos no nos debe confundir. Los canales financieros internacionales, al menos los aquí analizados, están fuertemente jerarquizados y las líneas de conexión son muy claras y reducidas a un selecto grupo de países.

El análisis territorial pone de manifiesto unos patrones de localización similares a los observados en otros países como Francia y España. Suiza concentra una parte sustancial de sus residentes en las 
principales ciudades, especialmente Zúrich y Ginebra, y en la "costa" Suiza del lago Leman, destino de referencia del turismo financiero internacional (Figura 7).

Figura 7. Residencia declarada de ciudadanos y sociedades con intereses en paraísos fiscales en torno al lago Leman (Suiza)

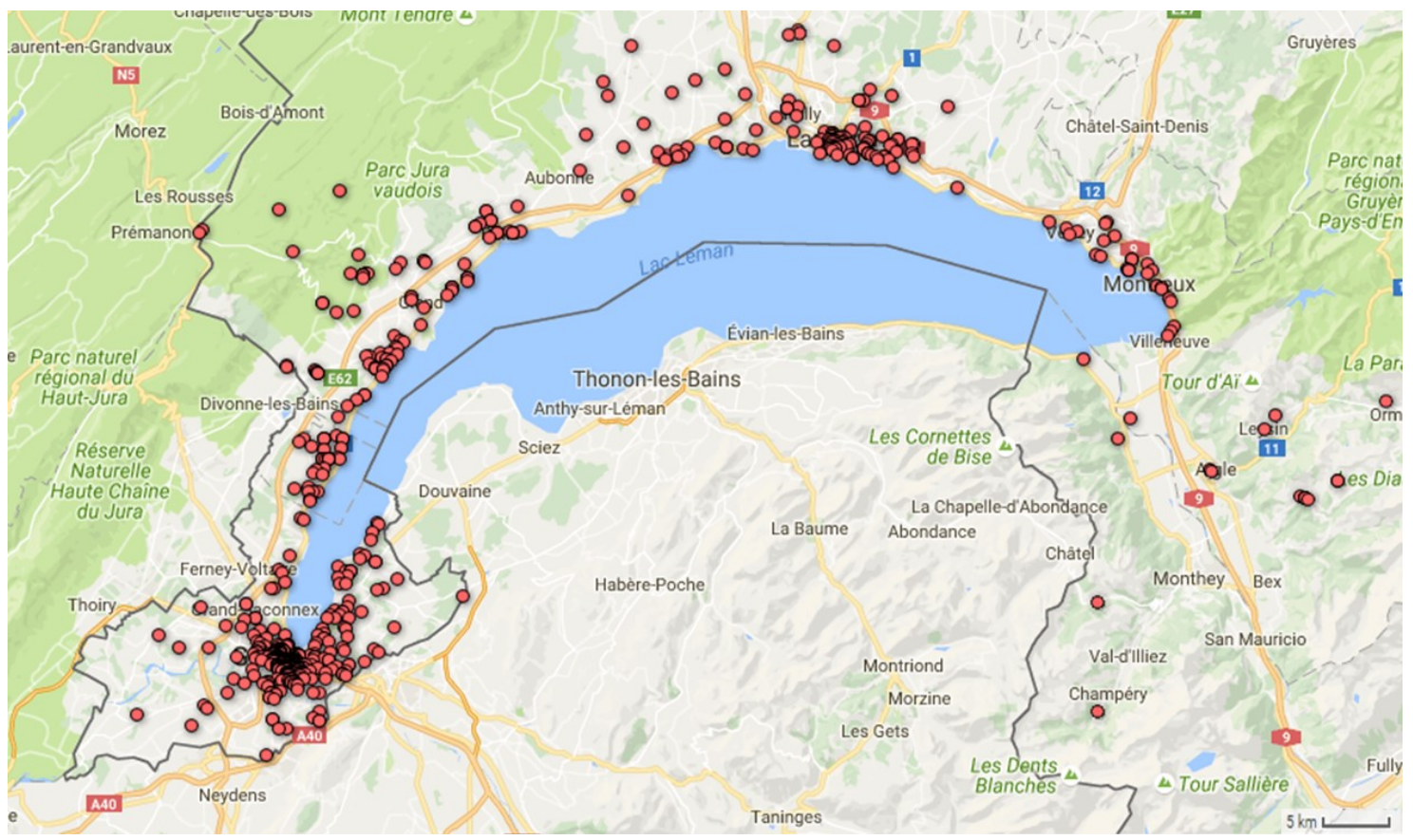

Fuente: ¿Una geografía de la corrupción? (Fernández Cela, 2017)

Se ha podido determinar el origen y destino de 3738 residentes y sociedades financieras que generan 39268 conexiones financieras con el exterior. Un 20,1\% de las cuales se concentran en torno a ocho grandes grupos, encabezados por la delegación en Ginebra de Mossack Fonseca, que mantiene cerca de 3000 relaciones sociedades localizadas en las Islas Vírgenes Británicas, Panamá o Bahamas entre las más destacadas.

Es significativo que el segundo conjunto en intermediación financiera sean propietarios de activos al portador, es decir, ciudadanos anónimos que son accionistas en sociedades localizadas en las Islas Vírgenes. Junto a ellos destaca la figura de Andre Zolty, un abogado suizo con conexiones en Israel, relacionado y posteriormente exonerado por actividades ligadas al blanqueo de dinero en Bolivia. Controla una importante red financiera internacional desde Suiza, con un gran número de ramificaciones al exterior, por encima incluso de grandes entidades bancarias como HSBC o UBS.

\subsection{Países del norte y oeste de Europa fuera de la UE}

Se trata de un espacio heterogéneo compuesto por aquellos países del Este que han quedado fuera de la UE y los casos excepcionales de Islandia y Noruega. Su aportación a la red europea de conexiones financieras es escasa, apenas un 4,7\% y prácticamente todas se encuentran establecidas en Rusia, que representa el $84,8 \%$ del total. 
La importancia de la red financiera rusa trasciende su espacio geopolítico de influencia y cuenta con una destacada capacidad de proyección exterior. No está a la altura de los grandes centros financieros internacionales, pero se encuentra inmediatamente detrás. El 85,5\% de todas las conexiones a paraísos fiscales procedentes de Rusia se dirigen a las Islas Vírgenes y Bahamas, es decir, exactamente los mismos espacios que el resto de los países de la UE. Otros países de destino de capital ruso son las Seychelles, Panamá y Niue. Las redes financieras de refugio de activos son globales, y no obedecen a patrones políticos muy diferentes de la UE, aunque las grandes fortunas estén localizadas en países con regímenes opuestos. En último término, con independencia de su origen geopolítico, rusos, europeos, chinos o estadounidense llevan su patrimonio a los mismos refugios seguros.

Llama la atención el escaso papel que representan las conexiones detectadas en Noruega, solo 179 con el exterior, y eso a pesar de su proyección financiera internacional articulada en torno al Oljefondet, el mayor fondo soberano del mundo. De nuevo debemos pensar en las limitaciones de la fuente analizada, porque no parece muy plausible que un país con una proyección exterior tan destacada en los mercados financieros internacionales tenga tan escasa presencia en la red de paraísos fiscales, aunque como se ha visto anteriormente, los países nórdicos son los que figuran en la escala de mayor cumplimiento fiscal. Al margen de Rusia, el único Estado con una estructura diversificada de interconexiones significativa con el exterior es Ucrania, que comparte los mismos países de destino que aquel.

Por otro lado, destaca el elevado nivel de concentración de las conexiones financieras en torno a un reducido número de sociedades, por encima de los niveles registrados en otros espacios. Un tercio de todas las relaciones con paraísos fiscales se vinculan a tres empresas: Global Wealth Management Center Limited; Trensis Enterprise Incorporated y especialmente Legal Consulting Services Limited, una sociedad que absorbe por sí misma el 21,0 \% de toda la red. Se trata de un intermediario altamente diversificado establecido en Rusia, con intereses en unas 2000 sociedades tecnológicas, energéticas o del sector aeroespacial entre otras muchas que se localizan en Bahamas, Niue, Panamá y naturalmente, las Islas Vírgenes.

\section{Conclusiones}

La morfología y configuración de la red financiera offshore en Europa va más allá de sus límites fronterizos tradicionales, hasta llegar a un amplio espacio de control geopolítico en torno a la región del Caribe y algunas islas del Pacífico, restos de antiguos imperios coloniales.

Se trata de una "Unión Europea offshore" que absorbe una parte sustancial de todas las conexiones financieras internacionales con origen y destino en Europa. Junto a este espacio, numerosos territorios dependientes y micro estados localizados en el interior de Europa, juegan un papel 
relevante en la cartografía financiera como puntos de interconexión con espacios financieros externos, procedentes en su mayor parte de China continental y Hong Kong. Esta estructura está pensada no solo para la actividad interna de las empresas localizadas en Europa, sino también para la captación indirecta de capital desde los centros financieros offshore de Extremo Oriente hacia el espacio de influencia política de la UE.

La estructura principal de la red se basa en 200000 conexiones financieras internacionales entre residentes de todos los países europeos que a través de varios hubs localizados en las islas del Canal, que dirigen sus depósitos al espacio caribeño y del Pacífico.

Un reducido conjunto de sociedades financieras internacionales son las que controlan, desde sus sedes centrales, el mantenimiento de esta red global por donde circula el capital. Es una gran tela de araña dispersa por todo el mundo y donde las diferencias legales y fiscales entre territorios desempeñan un papel determinante en su configuración. Sus patrones de localización en el interior del continente están ligados a la existencia de dos grandes ejes de concentración financiera. El primero de ellos comprende desde Irlanda al Norte de Italia y tiene su centro de gravedad en el triángulo Reino Unido-Luxemburgo-Países Bajos. El segundo eje es el de la costa mediterránea de Génova-San Remo-Niza-Marsella, se encuentra ligado a la localización de lujosos complejos turísticos por toda la costa.

Reino Unido juega en Europa un papel capital como conexión financiera con el exterior, ya que la mayor parte de los paraísos fiscales son islas de su antiguo imperio colonial. El desarrollo del Brexit puede sin duda modificar la cartografía financiera europea en la medida en que se puede producir un cortocircuito en estos movimientos de capital entre Reino Unido y la UE. De ser así supondría buscar otras alternativas en el continente para relocalizar sus capitales hacia espacios offshore.

Existe una cierta contradicción entre la organización política de la UE y sus controles contra la evasión de capital. Las situaciones singulares en las que se encuentran numerosos territorios de ultramar permiten vulnerar sistemáticamente los controles transfronterizos de capital. Esto es aprovechado por las grandes fortunas y empresas multinacionales para evitar entre otros el pago de impuestos en los países donde se generan sus beneficios. El mantenimiento de estas condiciones jurídicas "especiales" solo se explica si tiene como objeto evitar así la fuga de sus activos a otros territorios offshore que se encuentren fuera de su espacio de control geopolítico.

Agradecimientos: Me gustaría agradecer las sugerencias, correcciones y comentarios de las/os evaluadoras/es, que han revisado y mejorado sustancialmente el texto original. Soy totalmente responsable de los errores que puedan existir.

Declaración responsable: El autor declara que no existe ningún conflicto de interés en relación con la publicación de este artículo. 


\section{Bibliografía}

Aalbers, M B. (2017). Corporate Financialization. In D. Richardson, N. Castree, M. F. Goodchild, A. Kobayashi, W. Liu \& R. A. Marston (Eds.), International Encyclopedia of Geography: People, the Earth, Environment and Technology. https://doi.org/10.1002/9781118786352.wbieg0598

Aalbers, M. B. (2016). Financiarización corporativa. Enciclopedia Internacional de Geografía: Gente, la Tierra, Ambiente y Tecnología: Gente, Tierra, Ambiente y Tecnología , 1-11.

Alstadsæter, A., Johannesen, N., \& Zucman, G. (2017). Who Owns the Wealth in Tax Havens? Macro Evidence and Implications for Global Inequality. National Bureau of Economic Research.

Asgharian, H., Hess, W., \& Liu, L. (2013). A spatial analysis of international stock market linkages. Journal of Banking \& Finance, 37(12), 4738-4754.

Butkiewicz, J. L., \& Gordon, L. C. (2013). The economic growth effect of offshore banking in host territories: Evidence from the Caribbean. World Development, 44, 165-179.

Coe, N. M., Lai, K. P., \& Wójcik, D. (2014). Integrating finance into global production networks. Regional Studies, 48(5), 761-777.

Didier, T., Llovet, R., \& Schmukler, S. L. (2017): International financial integration of East Asia and Pacific. Journal of the Japanese and International Economies, 44, 52-66.

Dyreng S. D., \& Lindsey, B. P. (2009). Using financial accounting data to examine the effect of foreign operations located in tax havens and other countries on US multinational firms' tax rates. Journal of Accounting Research, 47(5), 1283-1316.

Fernández Cela, J. C. (2015). Estructura espacial de los flujos de Inversión Exterior Directa en España. Primeros pasos para la elaboración de una cartografía financiera. Geopolítica(s), 6(1), 107-136.

Fernández Cela, J. C. (2017). ¿ Una geografía de la corrupción? GeocritiQ.

Fernández Cela, J. C. (2018). Geografía financiera y paraísos fiscales. Implicaciones geopolíticas. Boletín IEEE, 9, 268-284.

Garcia-Bernardo, J. et al. (2017). Uncovering Offshore Financial Centers: Conduits and Sinks in the Global Corporate Ownership Network. Scientific Reports, 7(1), 6246.

Corpataux, J., Crevoisier, O., \& Theurillat, T. (2017). The territorial governance of the financial industry. In R. Martin \& J. Pollard, Handbook on the Geographies of Money and Finance (pp. 6985). Edward Elgar Publishing.

Geamanu, A., \& Dumitrana, M. (2015). Five Regional Perspectives of Constructing an Offshore Corporate Structure. SEA: Practical Application of Science, 7, 251-262. 
Giegold, S. (2017). How Luxembourg resisted European tax cooperation and made money with its circumvention. Greens/EFA in the European Parlament. Retrieved from https://www.greensefa.eu/en/article/news/how-luxembourg-resisted-european-tax-cooperation-and-made-money-withits-circumvention/

Gutiérrez de Pablo, G. (2015). Análisis jurídico de los paraísos fiscales y medidas para evitar sus efectos (Doctoral dissertation, Universidad de Málaga, Spain). Retrieved from https://riuma.uma.es/xmlui/bitstream/handle/10630/12862/TD_GUTIERREZ_DE_PABLO_ Gonzalo.pdf? sequence $=1 \&$ isAllowed $=\mathrm{y}$

Ibrahim, B. M., Brzeszczynski, J., \& Bhattacharjee, A. (2017). Geographical Changes in Influence of Stock Trading Centres Around the 2007 Global Financial Crisis (Financial Geography Working Paper, $\left.\quad n^{\circ} \quad 8\right)$. Retrieved from http://www. fingeo.net/wordpress/wpcontent/uploads/2017/10/WP8-Geographical-Changes-in-Influence-of-Stock-Trading.pdf

Johannesen, N., Langetieg, P., Reck, D., Risch, M., \& Slemrod, J. (2018). Taxing hidden wealth: The consequences of US enforcement initiatives on evasive foreign accounts, $n^{\circ} 24366$. National Bureau of Economic Research.

Knight, E., \& Wójcik, D. (2017). Geographical linkages in the financial services industry: a dialogue with organizational studies. Regional Studies, 51(1), 116-127.

Martin, R., \& Pollard, J. (Eds.) (2017). Handbook on the Geographies of Money and Finance. Edward Elgar Publishing.

Milesi-Ferretti, G. M., Strobbe, F., \& Tamirisa, N. T. (2010). Bilateral financial linkages and global imbalances: a view on the eve of the financial crisis.

Muellerleile, C. (2015). Speculative boundaries: Chicago and the regulatory history of US financial derivative markets. Environment and Planning A 47(9), 1805-1823.

OCDE (2017). Plan de acción contra la erosión de la base imponible y el traslado de beneficios, 2014. Retrieved from http://www.aedf-ifa.org/FicherosVisiblesWeb/Ficheros/Fichero79.pdf

Pan, F., Hall, S., \& Zhang, H. (2018). The geographies of financial activities within an emerging international financial center: the case of Beijing (Financial Geography Working Paper, $n^{\circ} 10$ ). Retrieved from http://www. fingeo.net/wordpress/wp-content/uploads/2018/01/WP10 Thegeographies-of-financial-activities_IFC-Beijing.pdf

Sokol, M. (2013). Towards a "newer" economic geography? Injecting finance and financialisation into economic geographies. Cambridge Journal of Regions, Economy and Society, 6(3), 501-515. Wójcik, D., Macdonald-Korth, D., \& Zhao, S. X. (2017). The political-economic geography of foreign exchange trading. Journal of Economic Geography, 17(2), 267-286. 
Zook, M., \& Grote, M. H. (2017). The microgeographies of global finance: High-frequency trading and the construction of information inequality. Environment and Planning A: Economy and Space, 49(1), 121-140.

Zucman, G. (2014). La riqueza oculta de las naciones. Barcelona: Pasado y Presente. 